\title{
Is Shared Leadership Shared?
}

\author{
Hidenori SATO ${ }^{\text {a) }}$ and Takahiko MAKABE ${ }^{\text {b) }}$
}

\begin{abstract}
This study examines the definition of shared leadership and how to measure it. Research so far defines shared leadership as possessing some basic common characteristics. However, the aggregation approach and the social network approach, which have different characteristics, coexist in terms of measurement methods. The former combines various existing leadership concepts and emphasizes the "leadership" part. The latter looks at how leadership is being shared; thus, the emphasis is on the "shared" part.
\end{abstract}

Keywords: shared leadership, aggregation approach, social network approach

\footnotetext{
a) Faculty of Business Sciences, University of Tsukuba, 3-29-1 Otsuka, Bunkyo-ku, Tokyo, Japan, sato.hidneori.fn@u.tsukuba.ac.jp

b) Graduate School of Business Sciences, Humanities and Social Sciences, University of Tsukuba, 3-291 Otsuka, Bunkyo-ku, Tokyo, Japan, lastride0915@gmail.com

HS and TM conceived of the presented idea. HS and TM collected data and HS summarized them. HS drafted the manuscript. TM helped to draft the manuscript. All authors read and approved the final manuscript.

The authors declare there are no competing interests.

A part of this article was presented at the ABAS Conference 2021 Summer (Sato \& Makabe, 2021).

(C) 2021 Hidenori Sato and Takahiko Makabe. This is an Open Access article distributed under the terms of the Creative Commons Attribution License CC BY 4.0 (Attribution 4.0 International) license. The CC BY 4.0 license permits unrestricted reuse, distribution, and reproduction in any medium, provided the original work is properly cited.
} 


\section{Introduction}

Leadership plays a key role in corporate management. ${ }^{1}$ Within the field of leadership, shared leadership has been the topic of many studies in recent years due to factors such as changes in organizational structures and the growth in knowledge work (Sweeney, Clarke, \& Higgs, 2019). Previous studies have demonstrated how shared leadership enhances team performance and the like and have also incorporated meta-analysis (Wang, Waldman, \& Zhang, 2014; Wu, Cormican, \& Chen, 2020).

In contrast, this study examines shared leadership from the perspective of its definition and measurement methods. Specifically, this study focuses on the extent to which shared leadership is defined and measured from a common standpoint. Research so far defines shared leadership as possessing some basic common characteristics. However, in terms of measurement methods, there are two approaches with different characteristics. Therefore, although these approaches address the same concept of shared leadership, they can be divided into two groups: those that emphasize the "leadership" part and those that emphasize the "shared" part.

\section{Definitions of Shared Leadership}

Shared leadership first became a leadership research topic in the mid-1990s (Zhu, Liao, \& Yam, 2018). ${ }^{2}$ An early study on the subject was Pearce and Sims (2002), who defined shared leadership by comparing it with vertical leadership, calling it "distributed influence

1 For example, Abe (2019), Kosuge and Takahashi (2016), Sato (2015), and Tsuda and Sato (2020) point out the importance of leaders in organizational transformation.

2 However, the starting point can be found in older studies. See also Döös \& Wilhelmson (2021). 
from within the team" (Pearce $\&$ Sims, p. 172) and "lateral influence among peers" (Pearce \& Sims, p. 176). Among other definitions that have been proposed are "an emergent state where team members collectively lead each other" (Avolio, Walumbwa, \& Weber, 2009), “an emergent property of a group where leadership functions are distributed among group members" (Drescher, Korsgaard, Welpe, Picot, \& Wigand, 2014, p. 772), and "an interactive influence processes in which leadership functions are dynamically shared among team members" (Liang, Knippenberg, \& Gu, 2021, p. 68).

Previous studies have therefore not adopted completely uniform definitions. Consequently, we can say that there is "a proliferation of definitions" (Zhu et al., 2018, p. 840) and that there are "inconsistencies in the definitions adopted" (Sweeney et al., 2019, p. 120).

Concurrently, however, it has also been stated that there is considerable commonality in the content of these definitions (Zhu et al., 2018). According to them, in many prior studies, the definitions of shared leadership have the following three characteristics in common.

The first is a focus on lateral influence among peers. Compared with vertical leadership, where a specific, formal leader is assumed to be leading, shared leadership emphasizes horizontal influence among team members.

The second is the viewpoint of leadership as an emergent team phenomenon. In previous studies, discussions considered leadership to be wielded by a particular person. In comparison, shared leadership is regarded as being generated by the team as a group. Therefore, the unit of analysis is not the individual or interpersonal relationships; rather, it is at the team level.

The third characteristic is that leadership roles and influence are dispersed across team members. That is, leadership is broadly dispersed throughout the team, rather than being centered on a 
particular individual.

Certainly, aforementioned studies do not all equally emphasize these three characteristics. For instance, Ensley, Hmieleski, and Pearce (2006) do not put any emphasis on the dispersion of leadership influence, whereas Lord, Day, Zaccaro, Avolio, and Eagly (2017) do not put any emphasis on lateral influence among peers. In addition, Nicolaides, LaPort, Chen, Tomassetti, Weis, Zaccaro, and Cortina (2014) add the characteristic that "team leadership functions are voluntarily shared" to the other three characteristics. Nevertheless, we can observe a certain degree of commonality in these definitions, particularly those that consider it a team-level phenomenon.

\section{Measurements of Shared Leadership}

There are two major approaches to measurement (Sweeney et al., 2019; Zhu et al., 2018).

The first is the aggregation approach. For example, Pearce and Sims (2002) use a questionnaire survey of team members to measure various types of leadership, such as aversive, directive, transactional, transformational, and empowering. The focus of the survey was to compare shared and vertical leadership; therefore, respondents were asked to respond to the same questions about team leaders and team members, and the latter responses were aggregated under the concept of shared leadership.

In particular, for transformational leadership, in the question, "My team leader (members) provides (provide) a clear vision of who and what our team is" (Pearce \& Sims, 2002, p. 192), when "my team leader" is the subject, it is measuring vertical leadership, and when "members" are the subject, it is measuring shared leadership. Other studies using this approach include Ensley et al. (2006), Hoch and Kozlowski (2014), Muethel, Gehrlein, and Hoegl (2012), and Song, Gu, 
and Cooke (2020).

In this approach, "team member" can be used in place of "leader" for the leadership metric, which means that it is possible to use transformational leadership and other existing concepts of leadership. This approach therefore emphasized the "leadership" part of shared leadership.

The other approach is the social network approach. Mehra, Smith, Dixon, and Robertson (2006) view shared leadership in terms of the centralization of leadership influence networks and posit that shared leadership occurs when team members are asked whom they regard as their leader. The more a network structure is focused on a particular individual the more centralized it is, whereas shared leadership occurs when there is less concentration and more dispersion. In addition, these questions do not clearly specify what is meant by "leader" and do not delve into the content of leadership to better comprehend the understanding of the survey targets themselves. A similar study that focuses on centralization is Small and Rentsch (2010).

Carson, Tesluk, and Marrone (2007) look at networks from a different perspective. ${ }^{3}$ This study regards shared leadership in terms of network density. The higher a network's density, the more likely it is that there will be shared leadership. The study asked each team member, "To what degree does your team rely on this individual for leadership?", and possible responses were given on a five-point scale ranging from "not at all" to "to a very great extent." The authors then calculated density by aggregating the team members' leadership assessments and dividing the sum by number of possible ties among team members. However, to find the number of possible ties, it was not actually necessary to depict the network using a name

3 Some argue that both centralization and density should be measured, but there have actually been very few cases in which both were done in the same study (DeRue, Nahrgang, \& Ashford, 2015). 
generator; therefore, strictly speaking, this did not constitute measurement of a social network.

Subsequent studies use similar methodologies (Ali, Wang, \& Johnson, 2020; Liu, Hu, Li, Wang, \& Lin, 2014; Lorinkova \& Bartol, 2021).

These social network approaches have the common characteristic of putting more emphasis on the impact within the team than on the leadership paradigm itself. Thus, they can be considered as emphasizing the "shared" part of shared leadership.

\section{Discussion}

As we have seen above, while studies of shared leadership have certain commonalities, their measurement methods take two approaches that possess different characteristics. Table 1 adds some newer studies based on Appendix S3 in Sweeney et al. (2019).

As for the differences in these two approaches, studies that take the social network approach show a stronger relationship with team performance more than studies that take the aggregation approach (D'Innocenzo, Mathieu, \& Kukenberger, 2016; Nicolaides et al., 2014; Wu et al., 2020).

In recent years, studies taking the social network approach have become more common than those taking the aggregation approach. Table 1 shows the increasing number of studies using the social network approach.

\section{Conclusion}

This study examined the definition of shared leadership and how to measure it. We found that the definitions have many commonalities, but that there are two types of measurement methods that possess different characteristics each. However, when 
Table 1. Measurements of shared leadership

\begin{tabular}{|c|c|c|}
\hline 1996 & Avolio, Jung, Murry, \& Sivasubramanium & Aggregation \\
\hline 2001 & Ensley \& Pearce & Aggregation \\
\hline 2002 & Pearce \& Sims & Aggregation \\
\hline 2002 & Sivasubramaniam, Murry, Avolio, \& Jung & Aggregation \\
\hline 2006 & Mehra, Smith, Dixon, \& Robertson & Social Network (Centralization) \\
\hline 2006 & Ensley, Hmieleski, \& Pearce & Aggregation \\
\hline 2007 & Carson, Tesluk, \& Marrone & Social Network (Density) \\
\hline 2008 & Solansky & Social Network (Density) \\
\hline 2010 & Hoch, Pearce, \& Welzel & Aggregation \\
\hline 2010 & Boies, Lvina, \& Martens & Aggregation \\
\hline 2010 & Small \& Rentsch & Social Network (Centralization) \\
\hline 2011 & Gupta, Huang, \& Yayla & Aggregation \\
\hline 2012 & Ishikawa & Social Network (Density) \\
\hline 2012 & Muethel, Gehrlein, \& Hoegl & Aggregation \\
\hline 2012 & Bergman, Rentsch, Small, Davenport, \& Bergman & Social network (Density) \\
\hline 2013 & Huang & Aggregation \\
\hline 2013 & Fausing, Jeppesen, Jønsson, Lewandowski, \& Bligh & Aggregation \\
\hline 2014 & Hoch \& Kozlowski & Aggregation \\
\hline 2014 & Liu, Hu, Li, Wang, \& Lin & Social network (Density) \\
\hline 2014 & Hoch & Aggregation \\
\hline 2015 & Mendez \& Busenbark & Social Network (Density) \\
\hline 2015 & Fausing, Joensson, Lewandowski, \& Bligh & Aggregation \\
\hline 2015 & Zhou, Vredenburgh, \& Rogoff & Social Network (Density) \\
\hline 2015 & Lee, Lee, Seo, \& Choi & Social Network (Density) \\
\hline 2015 & Mathieu, Kukenberger, D'Innocenzo, \& Reilly & Social Network (Density) \\
\hline 2017 & Zhou \& Vredenburgh & Social Network (Density) \\
\hline 2020 & Ali, Wang, \& Johnson & Social Network (Density) \\
\hline 2020 & Klasmeier \& Rowold & Social Network (Density) \\
\hline 2020 & Kukenberger \& D'Innocenzo & Social Network (Density) \\
\hline 2020 & Song, Gu, \& Cooke & Aggregation \\
\hline 2021 & Liang, Knippenberg, \& Gu & Aggregation \\
\hline 2021 & Lorinkova \& Bartol & Social Network (Density) \\
\hline 2021 & Mitchell \& Boyle & Social Network (Density) \\
\hline 2021 & Sinha, Chiu, \& Srinivas & Social Network (Density) \\
\hline
\end{tabular}

Source: Created based on Sweeney, Clarke, \& Higgs (2019), Appendix S3. The papers in bold boxes were added by the authors. 
we compare the two approaches, we found that the number of studies using the social network approach instead of the aggregation approach is increasing. It is possible that the measurement methods will not converge, but that one of these approaches will become the mainstream.

\section{Acknowledgments}

This work was supported by JSPS KAKENHI Grant Number JP19K13767.

\section{References}

Abe, M. (2019). Leader's episodic change and followers' continuous change: The case of Rakuwakai Otowa Hospital. Annals of Business Administrative Science, 18, 1-12. doi: 10.7880/abas.0181206a

Ali, A., Wang, H., \& Johnson, R. E. (2020). Empirical analysis of shared leadership promotion and team creativity: An adaptive leadership perspective. Journal of Organizational Behavior, 41(5), 405423.

Avolio, B. J., Jung, D. I., Murry, W., \& Sivasubramaniam, N. (1996). Building highly developed teams: Focusing on shared leadership processes, efficacy, trust, and performance. Advances in Interdisciplinary Studies of Work Teams, 3, 173-209.

Avolio, B. J., Walumbwa, F. O., \& Weber, T. J. (2009). Leadership: Current theories, research, and future directions. Annual Review of Psychology, 60, 421-449.

Bergman, J. Z., Rentsch, J. R., Small, E. E., Davenport, S. W., \& Bergman, S. M. (2012). The shared leadership process in decision-making teams. Journal of Social Psychology, 152(1), 17-42.

Boies, K., Lvina, E., \& Martens, M. L. (2010). Shared leadership and team performance in a business strategy simulation. Journal of Personnel Psychology, 9(4), 195-202.

Carson, J. B., Tesluk, P. E., \& Marrone, J. A. (2007). Shared leadership in 
teams: An investigation of antecedent conditions and performance. Academy of Management Journal, 50(5), 1217-1234.

DeRue, D. S., Nahrgang, J. D., \& Ashford, S. J. (2015). Interpersonal perceptions and the emergence of leadership structures in groups: A network perspective. Organization Science, 26(4), 1192-1209.

D'Innocenzo, L., Mathieu, J. E., \& Kukenberger, M. R. (2016). A metaanalysis of different forms of shared leadership-team performance relations. Journal of Management, 42(7), 1964-1991.

Döös, M., \& Wilhelmson, L. (2021). Fifty-five years of managerial shared leadership research: A review of an empirical field. Leadership. Advance online publication. doi: $10.1177 / 17427150211037809$

Drescher, M. A., Korsgaard, M. A., Welpe, I. M., Picot, A., \& Wigand, R. T. (2014). The dynamics of shared leadership: Building trust and enhancing performance. Journal of Applied Psychology, 99(5), 771-783.

Ensley, M. D., Hmieleski, K. M., \& Pearce, C. L. (2006). The importance of vertical and shared leadership within new venture top management teams: Implications for the performance of startups. Leadership Quarterly, 17(3), 217-231.

Ensley, M. D., \& Pearce, C. L. (2001). Shared cognition in top management teams: Implications for new venture performance. Journal of Organizational Behavior, 22(2), 145-160.

Fausing, M. S., Jeppesen, H. J., Jønsson, T. S., Lewandowski, J., \& Bligh, M. C. (2013). Moderators of shared leadership: Work function and team autonomy. Team Performance Management: An International Journal, 19(5/6), 244-262.

Fausing, M. S., Joensson, T. S., Lewandowski, J., \& Bligh, M. C. (2015). Antecedents of shared leadership: Empowering leadership and interdependence. Leadership \& Organization Development Journal, 36(3), 271-291.

Gupta, V. K., Huang, R., \& Yayla, A. A. (2011). Social capital, collective transformational leadership, and performance: A resource-based view of self-managed teams. Journal of Managerial Issues, 23(1), 31-45.

Hoch, J. E., Pearce, C. L., \& Welzel, L. (2010). Is the most effective team leadership shared? Journal of Personnel Psychology, 9(3), 105-116. 
Hoch, J. E. (2014). Shared leadership, diversity, and information sharing in teams. Journal of Managerial Psychology, 29(5), 541-564.

Hoch, J. E., \& Kozlowski, S. W. J. (2014). Leading virtual teams: Hierarchical leadership, structural supports, and shared team leadership. Journal of Applied Psychology, 99(3), 390-403.

Huang, C.-H. (2013). Shared leadership and team learning: Roles of knowledge sharing and team characteristics. Journal of International Management Studies, 8(1), 124-133.

Ishikawa, J. (2012). Transformational leadership and gatekeeping leadership: The roles of norm for maintaining consensus and shared leadership in team performance. Asia Pacific Journal of Management, 29(2), 265-283.

Klasmeier, K. N., \& Rowold, J. (2020). A multilevel investigation of predictors and outcomes of shared leadership. Journal of Organizational Behavior, 41(9), 915-930.

Kosuge, R., \& Takahashi, N. (2016). The survival of market orientation through artificial selection. Annals of Business Administrative Science, 15, 273-284. doi: 10.7880/abas.0161109b

Kukenberger, M. R., \& D'Innocenzo, L. (2020). The building blocks of shared leadership: The interactive effects of diversity types, team climate, and time. Personnel Psychology, 73(1), 125-150.

Lee, D. S., Lee, K. C., Seo, Y. W., \& Choi, D. Y. (2015). An analysis of shared leadership, diversity, and team creativity in an e-learning environment. Computers in Human Behavior, 42, 47-56.

Liang, B., Knippenberg, D., \& Gu, Q. (2021). A cross-level model of shared leadership, meaning, and individual creativity. Journal of Organizational Behavior, 42(1), 68-83.

Liu, S., Hu, J., Li, Y., Wang, Z., \& Lin, X. (2014). Examining the cross-level relationship between shared leadership and learning in teams: Evidence from China. Leadership Quarterly, 25(2), 282-295.

Lord, R. G., Day, D. V., Zaccaro, S. J., Avolio, B. J., \& Eagly, A. H. (2017). Leadership in applied psychology: Three waves of theory and research. Journal of Applied Psychology, 102(3), 434-451.

Lorinkova, N. M., \& Bartol, K. M. (2021). Shared leadership development and team performance: A new look at the dynamics of shared 
leadership. Personnel Psychology, 74(1), 77-107.

Mathieu, J. E., Kukenberger, M. R., D'Innocenzo, L., \& Reilly, G. (2015). Modeling reciprocal team cohesion-performance relationships, as impacted by shared leadership and members' competence. Journal of Applied Psychology, 100(3), 713-734.

Mehra, A., Smith, B. R., Dixon, A. L., \& Robertson, B. (2006). Distributed leadership in teams: The network of leadership perceptions and team performance. Leadership Quarterly, 17(3), 232-245.

Mendez, M. J., \& Busenbark, J. R. (2015). Shared leadership and gender: All members are equal ... but some more than others. Leadership \& Organization Development Journal, 36(1), 17-34.

Mitchell, R., \& Boyle, B. (2021). Too many cooks in the kitchen? The contingent curvilinear effect of shared leadership on multidisciplinary healthcare team innovation. Human Resource Management Journal, 31(1), 358-374.

Muethel, M., Gehrlein, S., \& Hoegl, M. (2012). Socio-demographic factors and shared leadership behaviors in dispersed teams: Implications for human resource management. Human Resource Management, 51(4), 525-548.

Nicolaides, V. C., LaPort, K. A., Chen, T. R., Tomassetti, A. J., Weis, E. J., Zaccaro, S. J., \& Cortina, J. M. (2014). The shared leadership of teams: A meta-analysis of proximal, distal, and moderating relationships. Leadership Quarterly, 25(5), 923-942.

Pearce, C. L., \& Sims, H. P. (2002). Vertical versus shared leadership as predictors of the effectiveness of change management teams: An examination of aversive, directive, transactional, transformational, and empowering leader behaviors. Group Dynamics Theory Research \& Practice, 6(2), 172-197.

Sato, H. (2015). Organizational change and temporal myopia. Annals of Business Administrative Science, 14, 323-333. doi: 10.7880 /abas. 14.323

Sato, H., \& Makabe, T. (2021, August). Is shared leadership shared? Paper presented at ABAS Conference 2021 Summer, University of Tokyo, Japan.

Sinha, R., Chiu, C.-Y. (Chad), \& Srinivas, S. B. (2021). Shared 
leadership and relationship conflict in teams: The moderating role of team power base diversity. Journal of Organizational Behavior, 42(5), 649-667.

Sivasubramaniam, N., Murry, W. D., Avolio, B. J., \& Jung, D. I. (2002). A longitudinal model of the effects of team leadership and group potency on group performance. Group \& Organization Management, 27(1), 6696.

Small, E. E., \& Rentsch, J. R. (2010). Shared leadership in teams. Journal of Personnel Psychology, 9(4), 203-211.

Solansky, S. T. (2008). Leadership style and team processes in selfmanaged teams. Journal of Leadership \& Organizational Studies, 14(4), 332-341.

Song, Z., Gu, Q., \& Cooke, F. L. (2020). The effects of high-involvement work systems and shared leadership on team creativity: A multilevel investigation. Human Resource Management, 59(2), 201-213.

Sweeney, A., Clarke, N., \& Higgs, M. (2019). Shared leadership in commercial organizations: A systematic review of definitions, theoretical frameworks and organizational outcomes. International Journal of Management Reviews, 21(1), 115-136.

Tsuda, K., \& Sato, H. (2020). Getting things done by middle manager. Annals of Business Administrative Science, 19, 241-251. doi: 10.7880/abas.0200901a

Wang, D., Waldman, D. A., \& Zhang, Z. (2014). A meta-analysis of shared leadership and team effectiveness. Journal of Applied Psychology, 99(2), 181-198.

Wu, Q., Cormican, K., \& Chen, G. (2020). A meta-analysis of shared leadership: Antecedents, consequences, and moderators. Journal of Leadership \& Organizational Studies, 27(1), 49-64.

Zhou, W., \& Vredenburgh, D. (2017). Dispositional antecedents of shared leadership emergent states on entrepreneurial teams. In C. BenHafaiedh \& T. M. Cooney (Eds.), Research handbook on entrepreneurial teams: Theory and practice. (pp. 164-184). Cheltenham, UK: Edward Elgar.

Zhou, W., Vredenburgh, D., \& Rogoff, E. G. (2015). Informational diversity and entrepreneurial team performance: Moderating effect of shared 
leadership. International Entrepreneurship and Management Journal, 11(1), 39-55.

Zhu, J., Liao, Z., \& Yam, K. C. (2018). Shared leadership: A state-of-theart review and future research agenda. Journal of Organizational Behavior, 39(7), 834-852. 